\title{
An open randomized controlled trial to compare the efficacy of two fixed dose combinations of artemesinin based combinations for uncomplicated falciparum malaria in Bangladesh
}

\author{
Samad $\mathrm{R}^{1}$, Rahman $\mathrm{MR}^{1}$, Yunus EB ${ }^{1}$, Hussain MA ${ }^{1}$, Arif $\mathrm{SM}^{2}$, Islam $\mathrm{MN}^{3}$, Hafiz SAMMA ${ }^{4}$, \\ Hossain $\mathrm{MM}^{3}$, Faiz $\mathrm{MA}^{1}$ \\ ${ }^{1}$ Member of Malaria Research Group (MRG), ${ }^{2}$ Department of Medicine, Dhaka Medical College, Dhaka, \\ ${ }^{3}$ National Malaria Control Programme (MNCP), ${ }^{4}$ Department of Medicine, Combined Military Hospital \\ (CMH), Chittagong. Email: rashedasamad@gmail.com
}

\begin{abstract}
National Malaria Control Program (NMCP) of Bangladesh has introduced Artemisinin Based Combination (ACT), Coartem ${ }^{(\mathrm{R})}$ (Artemether-Lumefantrine (AL), fixed dose combination, in the confirmed cases of uncomplicated $P$. falciparum malaria since 2004. Despite the reduction of mortality due to malaria, the development and spread of anti-malarial drug resistance wordwide posing a threat to the health services and will make it difficult to control malaria in Bangladesh in future. We need to have an alternative to Coartem which could be Artesunate-amodiaquine (AA) in a fixed dose combination (FDC), a cheaper altenative not yet evidenced to be effective and safe to our population. In this study we compared the efficacy and safety of Artemether + Lumefantrene (FDC, Coartem®) with Artesunate +Amodiaquine tablets (100/270 mg FDC) for the treatment of uncomplicated $P$. falciparum malaria in three high risk multi-drug resistant malaria prevalent areas of Bangladesh. It was an open label randomized controlled trial conducted between December 2008 and November 2009 in 4 upazillas in patients over the age 12 to 60 years diagnosed as a case of uncomplicated P.falciparum malaria. The outcome of the cases were measured as clinical response, parasitological response, defervescence time and parasite clearance time. Drug safety was assessed by comparing the adverse events. A total of 252 cases were randomized to receive Artesunate + Amodiaquine (AA group, 147 cases) and Artemether + Lumefantrene (AL group, 106 cases), one lost to follow up at day 28 in AA group. The distribution of the cases was comparable by age, sex and study sites. Treatment success' response was observed $100 \%$ in the AL group and AA group had 99\%, two failures with AA were late treatment failures and the difference was not statistically significant ( $\mathrm{p}>.1)$. The parasitological sensitive (S) response was observed in $97 \%$ of cases in AL group and $95 \%$ in the AA group, and was not a statistically significant difference. There was no significant difference in deffervescence time and parasite clearance time between two groups of cases. No serious adverse events were observed. The frequencies of minor adverse events were insignificantly different between the two treatment groups. The two ACT regimen, AA and AL had no significant difference in efficacy and safety for treatment of Uncomplicated Malaria in Bangladesh. However, there were few more failures with AA regimen compared to AL regimen, which was not statistically significant. Both these regimens can be used alternatively by the NMCP of Bangladesh as first-line treatment option.
\end{abstract}

\section{Introduction}

Bangladesh has updated the treatment regimen and guidelines of malaria with artemisinin based combination, Coartem ${ }^{(\mathrm{R})} \quad$ (artemether and lumefantrine) for diagnosed cases of uncomplicated $P$. falciparum malaria as the first line drug replacing CQ since 2004 ${ }^{1}$. In Bangladesh, malaria transmission is restricted to the hilly districts in the eastern and northern border areas. The majority of malaria cases are found in three districts of the Chittagong Hill Tracts $(\mathrm{CHT})^{2}$.
Emergence of drug resistance in $P$. falciparum was a serious problem to malaria control in Bangladesh. Resistance (RII+RIII) to chloroquine (CQ) has increased from $10 \%$ in 1979 to $45 \%$ in 1987 and $57 \%$ in $1992^{3}$. The failure to CQ and sulphadoxinepyremethamine (SP) was first documented in the country between 1968 and 1970 ${ }^{4}$. Thereafter, scanty data are available from the government's Malaria and Parasitic Disease Control unit (unpublished), showing in-vivo cure rates sensitive/resistence (S/RI) from various falciparum endemic areas until 1993 of $41 \%$ (466/1149) for 
CQ, 56\% (283/508) for SP and 100\% (328/328) for Quinine. In vitro sensitivity testing over the same period showed sensitivity (S) in 161/1049 (15\%), $215 / 343(63 \%), 284 / 284(100 \%)$ and $884 / 884$ (100\%) for CQ, SP, Quinine and Mefloquine respectively. After 1993, no systematically collected sensitivity data were available. Guidelines for treatment were available periodically, but not uniformly implemented. Few small-scale studies showed the existence of clinical and parasitological failure to $\mathrm{CQ}, \mathrm{CQ}+\mathrm{SP}$ and $\mathrm{SP}^{5-7}$.

More recent trials showed $>70 \%$ resistance to $\mathrm{CQ}^{8}$. High levels of in vitro mefloquine resistance also been reported in the area, despite the fact that this drug was not part of the national drug policy?. Several antimalarial drug combinations have subsequently been tried in the region ${ }^{\mathbf{1 0}}$. The fixed combination artemether/lumefantrine was proven to be highly effective for the treatment of uncomplicated falciparum malaria in the area, with a $92.4 \%$ cure rate and excellent tolerability ${ }^{\mathbf{1 1}}$. Based on the findings of this study as well as the high levels of resistance to other antimalarials, the Government of Bangladesh changed the recommended firstline treatment of parasitologically confirmed uncomplicated falciparum malaria to the artemisinin-based combination therapy (ACT) artemether/ lumefantrine, Coartem ${ }^{(\mathrm{R}) \mathbf{1}}$.

ACT is also recommended for use in the whole of sub-Saharan Africa. Fifteen out of 43 Sub-Saharan African countries have already adopted AA as firstline drug and the rest are at various stages of preparation for changes to the same regimen or toAL ${ }^{12,13}$.

It has been proven that efficacy of artemether/lumefantrine for the treatment of uncomplicated falciparum malaria in Bangladesh is still high ${ }^{\mathbf{1 4}}$. As emergence and spreading drug resistence is a serious problem wordwide puts on pressure for constant change of drug policy according to local evidences on sensitivity.

Every drugs for infectious diseases, especially antimalarials has exhibited a therapeutic life span and efficacy declines over time. The current recommended $\mathrm{AL}$ regimen for Bangladesh is also expected to have a decline in efficacy over time. The evidence on the efficacy of alternative ACTs should be available for Bangladesh especially as FDC as alternative first line anti-malaral drug. Also the cost of AL regimen is about 2.5 USD compared to the of AL regimen about 1.5 USD per tretment course. The other ACT Artesunate plus Mefloquine is about 4.5 USD and may not be suitable for Bangladesh on cost consideration at present.
This study was an attempt to evaluate and compare the efficacy of the current first line agent (Artesunate-Lumefantrine) with that of a relatively cheaper alterative (Artesunateamodiaquine) fixed dose regimen for use by NMCP.

\section{Materials and Methods}

Place and period of study: An Open randomized controlled trial was conducted between December 2008 and November 2009 in 4 upazillas of 3 high prevalent districts of Bangladesh. The areas were Naikhongchari, Kawkhali \& Kaptai and Matiranga Upazila Health Complexes of Banderban, Rangamati and Khagrachari Hill Districts respectively. Each of the UHCs serves as the lowest level in-patient facility for about 200,000 populations. Multi-drug resistant falciparum malaria has been documented from all these areas.

Sample size: Sample size was calculated as 132 (66 in each treatment group) cases in each District to detect a difference in efficacy of $25 \%$, with alpha error .05 and beta error .02 with $80 \%$ power and $95 \%$ confidence. The study cases were attending the out-patient (OPD) department passively.

Inclusion criteria: The inclusion criteria consisted of a) febrile patients with temperature $>100^{\circ} \mathrm{F}$ or a history of fever in last 48 hours. b) Blood slide positive for asexual forms of $\mathrm{P}$. falciparum with a parasite density between $500-250,000 / \mathrm{cmm}$, c) age between 12 and 60 years and d) agreed to Sign the informed consent to take part in the investigation and e) agreed to remain in hospital for 3 days and attend for follow up on days 7, 14 \& 28 day.

Exclusion criteria: The exclusion criteria consisted of a) pregnant and lactating women b) presence of any of the severe manifestations of malaria c) suspected or proven co-existence of other febrile illness d) co-infection with P. vivax e) known hypersensitivity to artesunate, lumefantrine and amodiaquine or to the excipients and f) history of taking any of these drugs over the last four weeks.

Randomisation procedure: A computer-generated simple randomization scheme was prepared in advance. Allocated treatments were kept in sealed opaque envelopes. After completion of formal enrolment procedures, allocated treatments were administered by project nurses.

Treatment allocation: Artemether + Lumefantrene

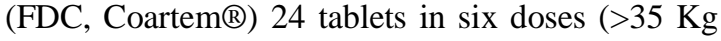
adult) were used manufactured by Novartis $®$ pharmaceuticals, Basel, Switzerland was administered at 0 and 8 hours on the first day, and then twice daily for two subsequent days. 
Artesunate+Amodiaquine tablets $(100 / 270 \quad \mathrm{mg}$ FDC) 2 tablets single dose daily ( $>35 \mathrm{Kg}$ adult) in three doses, manufactured in China, donated to the NMCP, were administered.

The dosages for children and adults weighing $<36$ $\mathrm{kg}$ appropriate FDC doses were applied as per WHO recommendation and adult doses were administered for all cases weighing $>36 \mathrm{~kg}$. Administration of each treatment dose of the drug were supervised by a team nurse and observed for one hour thereafter for vomiting. The total dose was replaced for vomiting within one hour of ingestion.

Follow up:

Subjects were followed-up on days 1, 2, 3, 7, 14 and 28 for clinical recovery or deterioration, sideeffects of drugs and new complaints if any by a study physician. Patients were modestly compensated for hospital stay and attendance (actual travel expenses) for follow-ups.

For microscopic examination of malarial parasite, Giemsa-stained blood films were examined by a trained laboratory technician in the public lowest level in-patient facility. 100 film fields of oilimmersion lens were examined for at least 15 minutes for the negative slides. Density of parasite were calculated by counting number of parasites per 200 leucocytes considering average white cell count of $8000 / \mathrm{cmm}$ for all patients. $5 \%$ of the positive slides and $10 \%$ of the negative slides were cross-examined by quality assurance microscopist and were found in agreement.

The outcomes of the cases were measured as clinical response, parasitological response, defervescence time and parasite clearance time and were defined as follows:

\section{A. Clinical Response:}

Early Treatment Failure: Study subjects with parasitaemia and persistent fever on day 3, as well as those whose condition has worsened before day 3.

Late Treatment Failures: Study subjects with initial clearance of fever (body temperature $<100^{\circ} \mathrm{F}$ ) on Day 3 but with persistent/recurrent parasitaemia and recurrent fever (body temperature $>100^{\circ} \mathrm{F}$ or history of fever) at a later time, with or without other symptoms.

Treatment success: The remainder (excepting those withdrawn because of a change of diagnosis). However some of the treatment successes might have asymptomatic persistent/recurrent parasitaemia.
B. Parasitological Response:

R III: Density on day 2 more than $25 \%$ of density on day 0 or alternative antimalarial therapy was required on or before day 2 .

R II: Positive on day 2, with a density not more than $25 \%$ of density on day 0 , and either positive on day 7 or alternative antimalarial therapy was required on any of days 2 to 7 .

R I: Negative or positive ( $<25 \%$ of day 0 ) on day 2 , negative on day 7 and positive anytime thereafter (within 28 days).

S: The remainder including those positive on day 2 with density less than $25 \%$ of day 0 and negative thereafter.

\section{Defervescence Time and Parasite Clearance}

Time: Defervescence $\left(<100^{\circ} \mathrm{F}\right)$ time was calculated from the six hourly temperature chart and parasite clearance time was calculated from the daily blood slide examinations.

Data Collection, Processing and Analysis: Individual patient's data were recorded on a printed questionnaire, entered, cleaned and analyzed using the software SPSS 10.0. Continuous variables were compared by t-test and by non-parametric methods. Discrete variables were compared either by $\chi^{2}$ test or Fisher's exact test where appropriate. 95\% confidence interval for the cure rates were described.

Ethical consideration: Institutional ethical clearance was obtained from Ethical eview committee of Chittagong Medical College. Patients were enrolled after taking consent from the patient/guardian. All the findings were recorded in semistractured questionnaire. Modest amount of compensation for wage loss due to hospital stay for patient/ guardian were compensated. Exact amount of travel cost were repayed for each follow up or unscheduled visit.

\section{Results}

A total of 252 cases were randomized to receive Artesunate +Amodiaquine (AA group, 147 cases) and Artemether Lumefantrene (AL group, 106 cases). The recruited numbers were less than target by site (66 in each group) because of not findings enough cases over the time period of the study and there was asymmetry in randomization between sites, e.g., Kawkhali upazilla used only AA regimen because of logistic supply problem. Hence the data was analyzed on total numbers (in all sites) for assessing comparative efficacy. 
The distribution of the cases was comparable by age, sex and study sites are shown in Table-I. The asymmetry in enrolled numbers between the two regimens was due to non-availability of AL drug at the Kawkhali site (a protocol violation).

'Treatment success' response was observed in all cases $(100 \%)$ in the AL group and the AA group had 144/146 (99\%, one lost to follow up) and the difference was not statistically significant ( $\mathrm{p}>.1)$. The two failures with AA were late treatment failures (Table II).

The parasitological sensitive (S) response was observed in $97 \%$ of cases in AL group and $95 \%$ in the AA group, and the difference was not significant statistically. All parasitological resistance types R-I through R-III was observed in AA group compared to only R-III response in the AL group (Table III). However the difference was not statistically significant.

There was no significant difference in deffervescence time and parasite clearance time between two groups of caes (Figure $1 \& 2$ ).

The frequency of adverse events was insignificantly different between the two groups of treatment (Table V). There was also no significant difference in response between different study sites.

Table I: Distribution of Age, sex and study site for study subjects

\begin{tabular}{llll}
\hline \multirow{6}{*}{ Age } & & $\begin{array}{l}\text { Artesunate } \\
\text { +Amodiaqui } \\
\text { ne } \\
\mathrm{n}=147\end{array}$ & $\begin{array}{l}\text { Artemether }+ \\
\text { Lumefantrene } \\
\mathrm{n}=106\end{array}$ \\
& $\begin{array}{l}\text { Median } \\
\text { (range) }\end{array}$ & 20 years & 20 years \\
& Range & $2-60$ years & $1-60$ years \\
Site & Male & $105(71.4)$ & $71(67.0)$ \\
& Female & $42(28.6)$ & $35(33.0)$ \\
& Ramu & $26(17.7)$ & $24(22.6)$ \\
& N Chari & $25(17.0)$ & $29(27.4)$ \\
& Kaptai & $23(15.6)$ & $16(15.1)$ \\
& Matiranga & $34(23.1)$ & $36(34.0)$ \\
& Kawkhali & $39(26.5)$ & $01(0.9)$ \\
\hline
\end{tabular}

Table II: Comparison of clinical response

\begin{tabular}{|c|c|c|c|c|}
\hline \multirow{2}{*}{$\begin{array}{l}\text { Clinical } \\
\text { Response } \\
\text { category }\end{array}$} & \multicolumn{2}{|c|}{$\begin{array}{l}\text { Artesunate+ Amodiaquine } \\
\text { (AA) }\end{array}$} & \multicolumn{2}{|c|}{$\begin{array}{l}\text { Artesunate }+ \\
\text { Lumefantrine (AL) }\end{array}$} \\
\hline & Frequency & Percent & Frequency & Percent \\
\hline ETF & 0 & 0.0 & 0 & 0.0 \\
\hline LTF & 2 & 1.37 & 0 & 0.0 \\
\hline Success & 144 & 98.63 & 106 & 100.0 \\
\hline Total & $146^{*}$ & 100.0 & 106 & 100.0 \\
\hline
\end{tabular}

*1 patient was lost to follow up

ETF (Early Treatment Failure): Study subjects with parasitaemia and persistent fever on day 3, as well as those whose condition has worsened before day 3 .
LTF (Late Treatment Failures): Study subjects with initial clearance of fever (body temperature $<1000 \mathrm{~F}$ ) on Day 3 but with persistent/recurrent parasitaemia and recurrent fever (body temperature $>10000 \mathrm{~F}$ or history of fever) at a later time, with or without other symptoms.

Success (Treatment success): The remainder (excepting those withdrawn because of a change of diagnosis). However some of the treatment successes might have asymptomatic persistent/recurrent parasitaemia.

Table III: Comparison of parasitological response

\begin{tabular}{|c|c|c|c|c|}
\hline \multirow{2}{*}{$\begin{array}{l}\text { Parasitic } \\
\text { response } \\
\text { category }\end{array}$} & \multicolumn{2}{|c|}{$\begin{array}{l}\text { Artesunate }+ \\
\text { Amodiaquine (AA) }\end{array}$} & \multicolumn{2}{|c|}{$\begin{array}{l}\text { Artesunate }+ \\
\text { Lumefantrine }(\mathrm{AL})\end{array}$} \\
\hline & Frequency & Percent & Frequency & Percent \\
\hline R III & 02 & 01.4 & 03 & 02.8 \\
\hline R II & 04 & 02.7 & 00 & 00.0 \\
\hline R I & 02 & 01.4 & 00 & 00.0 \\
\hline S & 139 & 94.6 & 103 & 97.2 \\
\hline Total & 147 & 100.0 & 106 & 100.0 \\
\hline
\end{tabular}

R III: Density on day 2 more than $25 \%$ of density on day 0 or alternative antimalarial therapy was required on or before day 2 .

R II: Positive on day 2, with a density not more than $25 \%$ of density on day 0 , and either positive on day 7 or alternative antimalarial therapy was required on any of days 2 to 7 .

R I: Negative or positive ( $<25 \%$ of day 0$)$ on day 2 , negative on day 7 and positive anytime thereafter (within 28 days).

$\mathrm{S}$ : The remainder including those positive on day 2 with density less than $25 \%$ of day 0 and negative thereafter.

Table IV: comparison of hematological response through paired comparison

\begin{tabular}{lllll}
\hline Measurement & \multicolumn{2}{l}{ Artesunate+ } & \multicolumn{2}{l}{ Artesunate +} \\
point pair & \multicolumn{2}{l}{$\begin{array}{l}\text { Amodiaquine } \\
\text { Paired mean }\end{array}$} & $\mathrm{P}$ & \multicolumn{2}{l}{$\begin{array}{l}\text { Lumefantrine }(\mathrm{AL}) \\
\text { Paired mean }\end{array}$} & $\mathrm{P}$ \\
& difference & Value & difference & Value \\
\hline HB0 vs HB14 & $-.71(.66)$ & $\mathrm{P}<.001$ & $-.63(.58)$ & $\mathrm{P}<.001$ \\
HB0 vs HB28 & $-.86(.77)$ & $\mathrm{P}<.001$ & $-.78(.63)$ & $\mathrm{P}<.001$ \\
HB14 vs HB28 & $-.16(.34)$ & $\mathrm{P}<.001$ & $-.16(.37)$ & $\mathrm{P}<.001$ \\
\hline
\end{tabular}

Haematological response was observed by hemoglobin estimation by colour matching method. It was observed in all patients on days 0 , 14, 28. $\mathrm{HB} 0=\mathrm{Hb}$ concentration at baseline, $\mathrm{HB} 14=\mathrm{Hb}$ concentration at day $14, \mathrm{HB} 28=\mathrm{Hb}$ concentration at day 28 
Table V: Comparison of adverse even and unscheduled visit

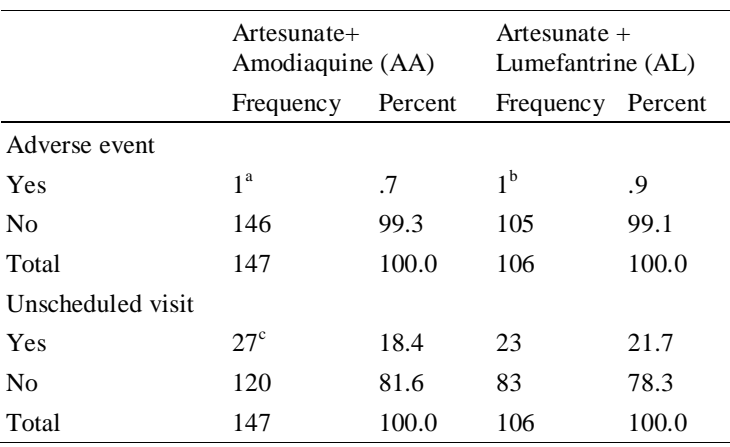

a. One patient experienced severe weakness

b. One patient experienced weakness and vomiting

Fig. 1: Defervasence time

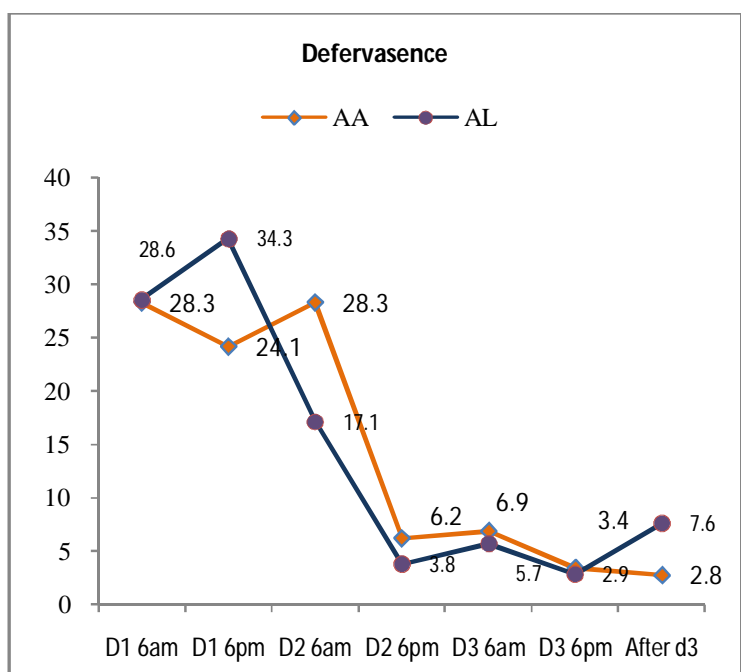

Defervescence (fever clearance) time was calculated from the six hourly temperature chart.

Fig. 2: Plasmodium falciparum clearance

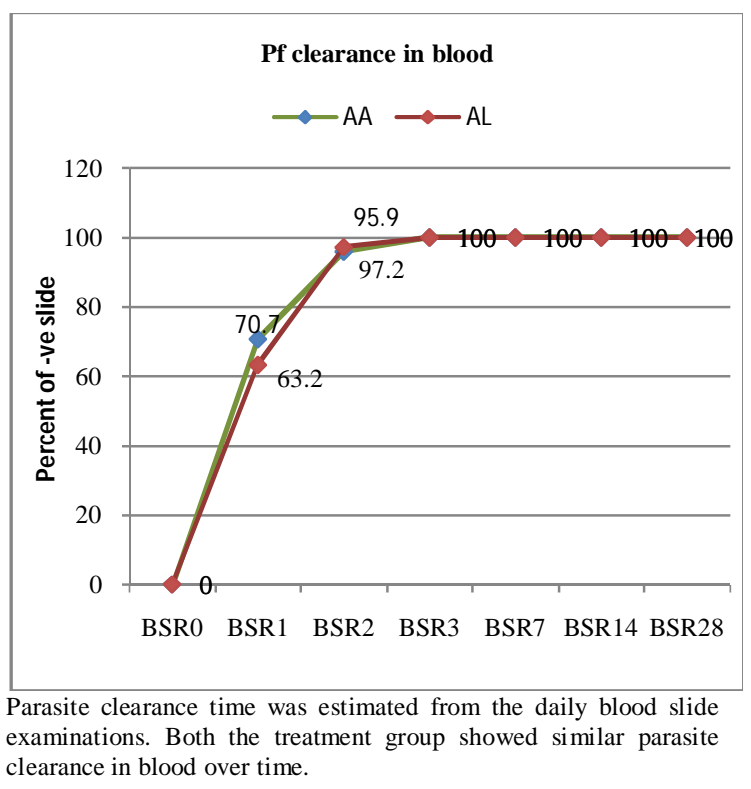

\section{Discussion}

Overall the two artemesinin-based combination Therapy (ACT) regimens, ArtemetherLumefantrine (AL) and Artesunate-amodiaquine (AA) applied in Fixed Dose Combinations (FDC), have high cure rates and had no significant difference in efficacy and safety in uncomplicated falciparum malaria (UM) in Bangladesh. However, there was few more treatment failures with AA compared to the AL regimen, which was not statistically significant. Both these regimens can therefore be used alternatively as first line treatment option for UM by the NMCP of Bangladesh.

The study on the efficacy of ArtemetherLumefantrine (AL), in the area dates from $2003^{11}$, showing a slightly lower efficacy of $92.4 \%$ PCRcorrected parasitological cure rate at Day 42. Based on the findings of the study, level of resistance, financial implications and policy, the NMCP of Bangladesh introduced ACT AL as the $1^{\text {st }}$ line antimalarial for uncomplicated falciparum malaria.

Emergence of drug resistance is posing a serious problem in Bangladesh. The degree of resistance of Plasmodium falciparum to CQ has increased tremendously. CQ resistance increased from $10 \%$ in 1979 to $45 \%$ in 1987 and $57 \%$ in 1992 $(\mathrm{RII}+\mathrm{RIII})^{7}$. Few trials showed more than $70 \%$ resistance of CQ against $P f^{\mathbf{8}}$. Increasing trend of resistance was observed against all antimalarials in use in Bangladesh. Even mefloquine, an antimalarial which was never used by NMCP, was available temporarily in the private sector also showed relatively high degree of resistance against $P f^{9}$. Several studies carried out to update the antimalarial drug regimen specially to identify a suitable first line drug, MSF-Holland (NGO) in collaboration with Government of Bangladesh carried out a study to measure the efficacy of several drug combinations including artemether plus lumefantrine (Coartem ${ }^{\circledR}$ ). The study documented overall efficacy of $92.4 \%$ of artemether-lumefantrtine against ${ }^{11}$. Based on the findings of the study, level of resistance, financial implications and policy, the Government of Bangladesh has updated the treatment regimen and guidelines of malaria with artemisinin based combination-Coartem (artemether and lumefantrine) as the first line drug replacing CQ since 2004.

The efficacy of alternative ACT, AA given as a FDC is supported by findings of clinical studies performed in locations throughout sub-Saharan 
Africa $^{15,16}$. The most widely adopted ACT regimens in Africa are artemether/lumefantrine (AL) and amodiaquine/artesunate (AA), each of which is first-line for uncomplicated P. falciparum malaria ${ }^{17}$. Democratic republic of Congo and Senegal are among the countries which included by $\mathrm{AA}$ as $1^{\text {st }}$ line regimen ${ }^{\mathbf{1 8 , 1 9}}$. Additionally it is worth to mention that AA, a user friendly (3day 3 doses) regimen is quite economic in comparison to $\mathrm{AL}$ regimen $^{20}$.

There were serious limitations in the conduct of the study, being limited in time, could not achieve desired sample size and the randomization process was not followed in one out of five sites and the comparison was unequal in recruited numbers. PCR corrected failure rates could not be performed.

The present study results substantiate the information on continued high efficacy of the $1^{\text {st }}$ line agent $\mathrm{AL}$ and its justification of continued use as the current $1^{\text {st }}$ line treatment option. The study also demonstrate non-inferiority of AA in terms of both safety and efficacy compared to AL applied in FDC formulation and hence may be considered an alternative $1^{\text {st }}$ line agent for the national malaria control program.

\section{References}

1. Malaria and Parasitic Disease Control Unit, Dhaka, Bangladesh. 2004; unpublished report.

2. Rosenberg R. Forest malaria in Bangladesh. III. Breeding habits of Anopheles dirus. American Journal of Tropical Medicine and Hygiene. 1982; 31: 192-201.

3. Malaria and Parasitic Disease Control Unit, Dhaka, Bangladesh. 1995; unpublished report.

4. Bangali AM, Rahman MR. Bangladesh Country Report presented in the "Training Workshop on Monitoring of Therapeutic Efficacy of Antimalarial Drugs against Falciparum Malaria”. 13-17 January, 1997; Anuradhapura, Srilanka. (not published).

5. Waiz A . Editorial. Malaria: Magnitude of the problem in Bangladesh. Bangladesh Medical Journal. 1984; 13(2\&3): I-IV.

6. Faiz MA, Ahmed M. In-vivo assessment of the sensitivity of Plasmodium falciparum to single dose pyremethamine-sulfadoxine in Bangladesh where chloroquine resistant falciparum malaria has been detected. J. Bang. Col. Phys. Surg. 1986; 4 :( 1): 7-9.

7. Rahman MR, Hassan MR, Faiz MA, Samad R, Paul B \& Jalil MA. Monitoring efficacy of commonly used antimalarials by a 14-day in-vivo test in a new settler's camp in endemic zone at Cox's Bazar. Bangladesh Medical Research Council. 1998; 24(3): 67-74.
8. Rahman MR, Paul DC, Rashid M, Ghosh A, Bangali AM, Jalil MA, Faiz MA. A randomized controlled trial on the efficacy of alternative treatment regimens for uncomplicated falciparum malaria in a multidrugresistant falciparum area of Bangladesh_-narrowing the options for the National Malaria Control Program? Transactions of Royal Society of Tropical Medicine and Hygiene. 2001; 95: 661-667.

9. Noedl H, Faiz MA, Yunus EB, Rahman MR, Hossain MA, Samad R, Miller RS, Pang LW, Wongsrichanalai C. Drug resistant malaria in Bangladesh: an in vitro assessment American Journal of Tropical Medicine and Hygiene. 2003; 68(2): 140-142.

10. Rahman, M., Rahman, MR., Bangali, AM, Das S, Talukder, MR, Ringwald P. Efficacy of combined chloroquine and sulfadoxine-pyrimethamine in uncomplicated Plasmodium falciparum malaria in Bangladesh. Transaction of Royal Society of Tropical Medicine and Hygiene. 2004; 98(7): 438-441.

11. Borek IV, Maung UA, Peters A, Liem L, Kamal M, Rahman M, Rahman MR, Bangali AM, Dash S, Barends M, Faiz AM. Efficacy of combined chloroquine and sulfadoxine-pyrimethamine, mefloquine + artesunate and artemether + lumefantrine combination therapies to treat Plasmodium falciparum malaria in the Chittagong Hill Tract, Bangladesh. Transaction of Royal Society of Tropical Medicine and Hygiene. 2005; 99: 727-735.

12. World Health Organization. Guidelines for malaria treatment.[http://www.who.int/malaria/docs/ Treatment Guidelines 2006. pdf].

13. Arrow J, Panosian CB, Gelband H, (Eds): Saving lives, buying time: Economics of malaria drugs in an age of resistance. Washington DC, USA:National Academy Press; 2004.

14. Rahman MR, Dondorp AM, Day NPJ, Lindegardh N, Imwong M, Faiz MA, Bangali AM, Kamal ATM, Karim J, Kaewkungwal J, Singhasivanon P. Adherence and efficacy of supervised versus non-supervised treatment with artemether/lumefantrine for the treatment of uncomplicated Plasmodium falciparum malaria in Bangladesh: a randomised controlled trial. Transactions of Royal Society of Tropical Medicine \& Hygiene. 2008; 102 (9): 861-867.

15. Ndiaye JL, Randrianarivelojosia M, Sagara I, Brasseur P, Ndiaye I, Faye B, Randrianasolo L, Ratsimbasoa A, Forlemu D, Moor VA, Traore A, Dicko Y, Dara N, Lameyre V, Diallo M, Djimde A, Same-Ekobo A, Gaye O. Randomized, multicentre assessment of the efficacy and safety of ASAQ - a fixed-dose artesunateamodiaquine combination therapyin the treatment of uncomplicated P. falciparum malaria. Malaria Journal. 2009; 8:125.

16. Sirima SB,Tiono AB, Gansané A, Diarra A, Ouédraog A, Konaté AT, Kiechel JR, Morgan CC, Olliaro PL, Taylor WRJ. The efficacy and safety of a new fixeddose combination of amodiaquine and artesunate in 
young children with acute uncomplicated Plasmodium falciparum. Malaria Journal. 2009; 8:48.

17. World Health Organization. Facts on ACTs; January 2006 update.

18. Bonnet M, Broek IVD, Herp MV, Urrutias PPP, Kyomuhendo J, Ndosimao CN, Ashley E, Guthmann JP. Varying efficacy of artesunate+amodiaquine and artesunate+sulphadoxine-pyrimethamine for the treatment of uncomplicated falciparum malaria in the Democratic Republic of Congo: a report of two in-vivo studies. Malaria Journal. 2009; 8:192.
19. Ndiaye J, Faye B, Gueye A, Tine R, Ndiaye D, Tchania C, Ndiaye I, Barry A, Cisse B, Lameyre V, Gaye O. Repeated treatment of recurrent uncomplicated Plasmodium falciparum malaria in Senegal with fixed-dose artesunate plus amodiaquine versus fixed-dose artemether plus lumefantrine: a randomized, open-label trial. Malaria Journal 2011; 10:237.

20. SANOFI-AVENTIS. Application for an inclusion in the WHO essential drug list-subdivision 6.5.3 antimalarial medicines-curative treatments; April 2006. 